Bird Conservation International (2023), 33: e4, 1-15. C The Author(s), 2021. Published by Cambridge University Press on behalf of Bird Conservation International. This is an Open Access article, distributed under the terms of the Creative Commons Attribution licence (https://creativecommons.org/licenses/by/4.0/), which permits unrestricted re-use, distribution, and reproduction in any medium, provided the original work is properly cited. doi:10.1017/S095927092100037X

\title{
Aleutian Tern Onychoprion aleuticus abundance estimates at four globally significant colonies
}

\author{
HEATHER RENNER ${ }^{1 *}$ (D), MARTIN RENNER ${ }^{2}$, DON LYONS ${ }^{3}$, VLADIMIR ZYKOV $^{4}$, \\ ZOYA REVYAKINA ${ }^{4}$ and SUSAN OEHLERS ${ }^{5}$
}

${ }^{1}$ U.S. Fish and Wildlife Service, Alaska Maritime National Wildlife Refuge, 95 Sterling Highway Suite 1, Homer AK 99603, USA.

${ }^{2}$ Tern Again Consulting, 811 Ocean Drive Loop, Homer AK 99603, USA.

${ }^{3}$ National Audubon Society, 12 Audubon Road, Bremen, ME 04551 and Oregon State University, 104 Nash Hall, Corvallis, OR 97331, USA.

${ }^{4}$ IRC "Fauna", Komsomolskaya str. 241A, ap.14 Yuzhno-Sakhalinsk 693023, Russia.

${ }^{5}$ U.S. Forest Service, 421 Ocean Cape Road, Yakutat AK 99689, USA.

*Author for correspondence; email: heather_renner@fws.gov

(Received 30 December 2020; revision accepted 23 August 2021)

\section{Summary}

Aleutian Tern Onychoprion aleuticus numbers have been in steep decline at known Alaskan breeding colonies in recent decades (IUCN recently uplisted to 'Vulnerable'). Available data suggest that most of the species may currently breed in Russia. Efforts to document global abundance and trends have been hampered by remoteness of colonies, lack of a formal monitoring programme, and the absence of reproducible population estimates with quantifiable errors, especially for large colonies. We surveyed four historically large colonies in Russia (2018) and Alaska (2019), which together may comprise $30-50 \%$ of the global breeding population. At each colony we obtained high resolution aerial photographs using a small Unmanned Aircraft System (sUAS). The large size of the colonies and the minimum altitude required to identify terns made it impractical to collect imagery of the entire colony. Instead, we employed a sampling approach, with sample locations selected based on spatially balanced acceptance sampling. Statistically sampled, low altitude sUAS images provided a fast, reproducible, and rigorous count of abundance for geographically large colonies, with low disturbance, and were generally consistent with concurrent ground-based observations. Concurrence among observers in photo counts indicated high precision in counts of attending birds and unattended nests, although species attribution in mixed tern colonies remains a source of significant uncertainty. Our results indicate that the four colonies surveyed here together supported $<2,500$ pairs of Aleutian Terns in the survey years. None of the colonies approached their peak size reported previously, likely due to recent predation, long-term decline, cold early season weather, or other factors. If these reduced colony sizes are representative of the current conditions, the implications for the global population would be dire.

Keywords: Alaska, conservation, Onychoprion aleuticus, Sterna camtschatica, Sakhalin Island, aerial survey, sUAS

\section{Introduction}

Worldwide, coastal populations of terns (Sternini) are under increasing stress from energetic storms and rising sea levels (Erwin et al. 2010, Chen et al. 2015), climate and fishing induced changes in food 
supplies (Velarde et al. 2015), and offshore wind development (Everaert and Stienen 2007, Newton and Little 2009). In addition to these modern conservation issues, legacy effects of displacement by subsidised gull populations (Kress et al. 1983), contaminants such as DDT (Nacci et al. 2016), mortality in wintering areas (Hays et al. 1997), and human development (Erwin et al. 2003) may still linger in some regions. Numbers of breeding pairs at known colonies of Aleutian Terns Onychoprion aleuticus across Alaska have been in steep decline in recent decades (Renner et al. 2015), which led IUCN to uplist the species to 'Vulnerable' (BirdLife International 202I). Available data suggest that the majority of the species may currently breed in the Russian Far East. Some observers have speculated that the Russian population of Aleutian Terns is stable or increasing (e.g. Tiunov and Blokhin 2014). Extensive survey data supporting this perspective are not widely available, however, and survey methods are not well established or standardized across the species' range. Major declines at colonies in Alaska are a serious conservation concern. The implications would be less bleak if the Russian populations were in fact large and stable. According to Tiunov and Blokhin (2014), Sakhalin Island in the Russian Far East supports $36-39 \%$ of the world's breeding population, with $\sim 25 \%$ of the global population (est. 31,131; Renner et al. 2015) concentrated on three islands in northern Sakhalin: Chaika, Lyarvo, and Wrangel. This may be a much larger proportion when declines in Alaska are considered. The only remaining large Aleutian Tern colony in Alaska, with at least hundreds of pairs, is located in the eastern Gulf of Alaska at Black Sand Spit, near Yakutat. Unless a large colony has gone undetected, which seems unlikely, these four colonies together are the largest for this species worldwide and may represent up to half the global breeding population.

Aleutian Terns nest in about 200 coastal colonies across Alaska and Russia (Renner et al. 2015), on islands as well as the mainland. Methods to enumerate nesting Aleutian Terns have been problematic (McDonald et al. 2018, 2019, Magness et al. 2019). Flying birds can be counted reasonably accurately in small colonies, but this becomes troublesome for large colonies that cannot be counted all at once.

Compared to most other tern species, Aleutian Terns nest at low densities; dispersed colonies can cover large areas. Several anti-predator adaptations contribute to censusing challenges (see North 2020). They often nest interspersed with more aggressive tern species (Arctic Tern Sterna paradisaea in Alaska and Common Tern Sterna hirundo longipennis in Russia). Birds flush easily when disturbed, and often temporarily flee the colony; older chicks are mobile and hide in vegetation. Chicks, eggs, and nests are cryptically patterned. Further challenges come from an apparently high recent rate of nest and colony abandonment (possibly high sensitivity to repeated human and/or predator disturbance; Corcoran et al. 2018) and a capacity for asynchronous nesting and withinseason dispersal (e.g. Oehlers 2020). Aleutian Terns have variable habitat associations but are often found within continuous, low, vegetation cover. They are also difficult to observe and enumerate outside the breeding season, being highly dispersed (Goldstein et al. 2019) and with plumage similar to more abundant tern species (Yordan et al. 2019).

In recent years, small, unmanned aircraft systems (sUAS) have become widely used tools to survey seabird abundance at breeding colonies, including surveys of multiple tern species (Hodgson et al. 2016, Bell and Harborne 2019, Valle and Scarton 2021). Magness et al. (2019) showed that sUAS surveys could provide a useful and low disturbance means to estimate numbers of Aleutian Terns, although the ability to distinguish it from similar species remains unresolved.

We used sUAS and visual estimates to survey Chaika, Lyarvo, and Wrangel Islands, Russia, in 2018 and Black Sand Spit, Alaska in 2019. Our objectives were:

(I) Conduct field observations at historically large Aleutian Tern colonies within Russia and Alaska to improve understanding of current population status, habitat use and threats;

(2) Estimate numbers of nesting terns at numerically large, spatially dispersed colonies using sUAS aerial images to provide a baseline for future trend estimates;

(3) Compare estimated numbers from sUAS flights to numbers obtained by other survey methods (flush counts and systematic nest-count transects); and,

(4) Provide a common context for survey methods and information transfer for both Russian and American scientists. 


\section{Study Area}

\section{Russia}

In Russia we visited three islands in shallow lagoons on the north-east Sakhalin coast (Figure I). Nabil Bay is a lagoon on eastern Sakhalin, harbouring nine islands, one of which (Chaika Island) hosts a colony of Aleutian and Common Terns; others have large Common Tern colonies. Chaika Island and the Chayachyi Islands have natural monument status. Chaika Island has been reported to have numbers of nesting pairs varying between 587 and 2,151 Aleutian Terns and 1,555-4,000 Common Terns in visual flush surveys from 1981 to 2012 (Tiunov and Blokhin 2014).

Nyisky Bay is a lagoon on the north-eastern coast of Sakhalin; within, Lyarvo Island hosts a colony of Aleutian and Common Terns. Lyarvo Island has been reported to have numbers varying between 500 and 2,000 nesting pairs of Aleutian Terns and 1,000-4,000 pairs of Common Terns in visual flush surveys from 1976 to 2012 (Tiunov and Blokhin 2014).

Piltun Bay is the largest lagoon on Sakhalin's north-eastern coast. The Aleutian Tern colonies are located in the north part of Major Wrangel Island, on Minor Wrangel Island, and in smaller numbers on the swampy portion of the marine sand bar separating Piltun Bay from the Sea of
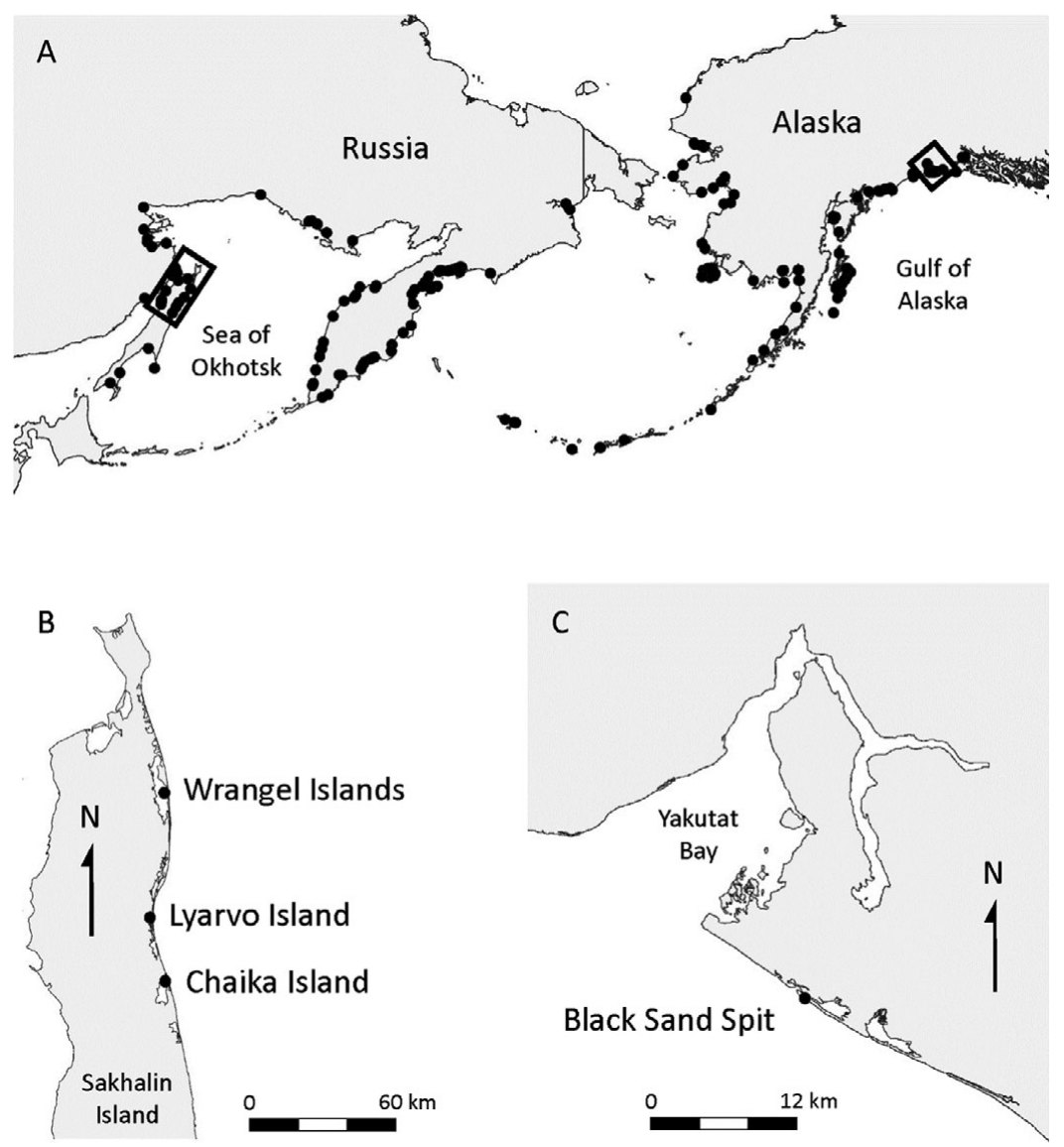

Figure 1. Aleutian Tern colonies across the breeding range (A; Renner et al. 2015) with those surveyed on Sakhalin Island, Russia, and Alaska, USA, during this study indicated in insets (B and C, respectively). 
Okhotsk. A natural monument of regional significance, 'The Wrangel Islands' was established on the Major and Minor Wrangel Islands with the main purpose of protection for the Aleutian and Common Tern colony. Estimates of breeding tern abundance between 1987 and 2012 were reported by Tiunov and Blokhin (2014) based on visual surveys of flushed birds, or nest censuses, to range from 400 to 3,000 Aleutian Tern pairs and 500-5,000 Common Tern pairs. Based on nest count transects, Zykov and Revyakina (2019) reported a similar range of nest numbers between 1999 and 2018: Aleutian Tern 482-4,593, Common Tern 1,350-4,313. All three Russian colonies visited are low-lying and covered in short vegetation of beach rye and heathers. Bushes and trees are rare or absent.

\section{Alaska}

Black Sand Spit (Figure I) is a narrow barrier beach, tidally connected to the mainland. Arctic and Aleutian Terns nest in a mixed colony in varying locations along the $12-\mathrm{km}$ long spit. An early documented observation indicates that Aleutian Terns have been breeding on Black Sand Spit since at least 1916 (Walker 1923). Estimates have been as high as 3,000 Aleutian Terns in some years, making Black Sand Spit by far the largest known colony in Alaska (Renner et al. 2015). In Alaska, previous published estimates have been numbers of terns rather than numbers of pairs. Black Sand Spit is sparsely vegetated, having many areas of open sand and vegetation dominated by beach rye.

\section{Methods}

We surveyed the three major colonies on the north-east coast of Sakhalin Island on 20-27 June 2018: Chaika Island (50 ha), Lyarvo Island (101 ha), and the Wrangel Islands (26 ha total). A year later, in late June 2019, we surveyed the Alaskan Aleutian Tern colony at Black Sand Spit, (312 ha). All surveys were conducted during the tern incubation or early chick-rearing period. No chicks of any tern species were observed during opportunistic nest inspections in Russia. Most birds were still on eggs during the survey at Black Sand Spit, but some adults were seen carrying fish, indicating that the first chicks had just hatched.

\section{Visual observations}

At Lyarvo and Chaika Islands in 2018, we walked the entire colony and collected preliminary assessments of tern colony size and species composition based on counts of flushed birds and the size and density of nesting areas. Two observers estimated species ratios of birds in flight at roughly equally spaced intervals while walking across the island. The Wrangel Islands are typically covered with densely nesting terns, so are impossible to access without flushing birds off nests. Because detailed nest count data were available from a transect-based survey (described below), we did not conduct additional counts of flushed birds in the air.

At Black Sand Spit, two different types of visual surveys were accomplished in 2019, several days apart. First, a flush count following the "modified direct count method" (Pyare et al. 2013) was conducted on 20 June. For this method, two observers assess the colony's distribution across the landscape and decide on the starting point for a transect running parallel through the colony at the approximate midpoint. The observers approach the colony and stop at certain points, where they count all terns up to $90^{\circ}$ on both sides of them up to an agreed landmark. They estimate and agree on the species ratio at each survey point. The observers then walk to the next landmark and repeat the procedure, until they have reached the limits of the colony. It is assumed that most terns are flushed during the approach to the next sampling point and that all terns are counted in the $180^{\circ}$ field-of-view in front of the observers. The estimates from each observer are then averaged for the total population estimate. This method is believed to be biased towards underestimating the number of individuals, and presumably includes flushed birds off nests as well as some nonattending mates. 
On 23 and 24 June 2019 (concurrent with the sUAS surveys), a single observer viewed the colony from the mainland (i.e. a distance where no flushing occurred). The observer made repeated counts of terns in the air, which were subsequently averaged. Species identification was not attempted. This method provides an estimate of flying birds only, which are presumed (during the incubation period, with one partner attending the nest) to represent failed/non breeders, or non-attending mates of birds that are sitting on nests.

\section{Transect-based nest survey}

On the Wrangel Islands, two observers surveyed a strip transect which has been consistently surveyed on 25 June (incubation period) during 2004, 2008 and 2011-2018. Tern nests were recorded on a 2-m wide, 9,062 $\mathrm{m}$ long transect, zig-zagging across the entire island (Figure 2). Species of clutches were determined by egg colour and shape (Baicich and Harrison 2005, VZ unpubl. data). Nest density of each species was calculated along the transect and converted to a population estimate for the entire island. In 2018, an additional transect survey ( $2 \mathrm{~m}$ wide, $5,384 \mathrm{~m}$ long) was conducted on 3 July, outside the historical count period, due to late nesting phenology. We used the 25 June survey to compare with our sUAS estimates because the timing was only one day apart.

\section{sUAS surveys}

At each colony we obtained high resolution aerial photographs using a small Unmanned Aerial Vehicle (sUAS, "drone"). The sUAS was a white DJI Phantom Pro 4 quadcopter $(1,388 \mathrm{~g}, 8 \mathrm{IdB})$ featuring a gimballed digital camera with a 12.4-megapixel sensor and $8.8 \mathrm{~mm}$ fixed focal length lens (equivalent to $24 \mathrm{~mm}$ on $35 \mathrm{~mm}$ film). Flights were launched from a skiff, or from the nearby mainland, or where sufficiently low nest densities allowed, from areas on the island not occupied by terns. All launch sites were $>200 \mathrm{~m}$ from areas occupied by terns. The large size of the islands and

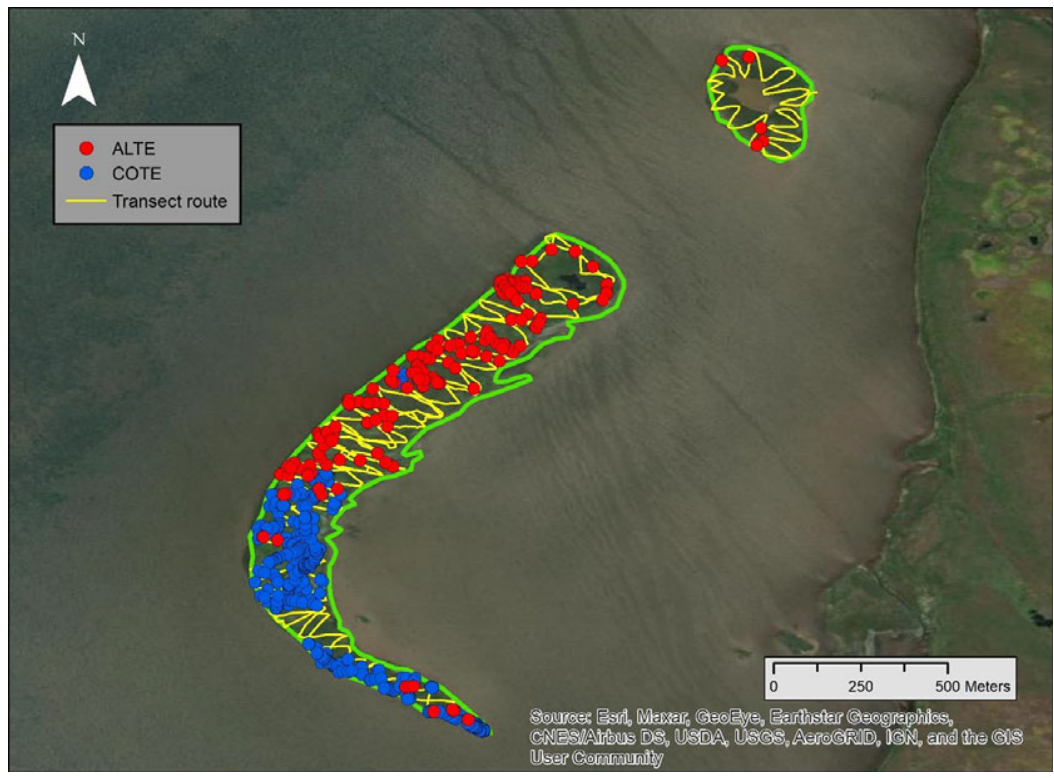

Figure 2. Survey route of 2-m wide transect recording tern nests on the Wrangel Islands. Circles indicate Aleutian and Common Tern nests observed on 25 June 2018. 
Table 1 . Counts of terns on the ground and unattended nests in sUAS photos of randomly sampled points (each $35 \mathrm{om}^{2}$ ) and extrapolated Aleutian Tern abundance for four colonies in Alaska and Russia, 2018 and 2019. Birds on the ground plus empty nests from flushed birds is assumed to approximate the number of nesting pairs. ALTE $=$ Aleutian Tern, COTE $=$ Common Tern, ARTE $=$ Arctic Tern.

\begin{tabular}{|c|c|c|c|c|c|c|c|c|}
\hline & ALTE & $\begin{array}{l}\text { COTE/ } \\
\text { ARTE }\end{array}$ & unid. & $\begin{array}{c}\# \\
\text { images }\end{array}$ & $\begin{array}{l}\text { island } \\
\text { area }\end{array}$ & $\begin{array}{l}\% \text { of is. } \\
\text { sampled }\end{array}$ & $\begin{array}{c}\text { ALTE } \\
\text { (estimate) }\end{array}$ & $\begin{array}{l}\text { All terns } \\
\text { (estimate) }\end{array}$ \\
\hline Chaika & 3 & o & o & 245 & $50 \mathrm{ha}$ & $17.1 \%$ & $19(6,56)$ & $19(6,56)$ \\
\hline Lyarvo & 85 & 86 & 67 & 278 & IOI ha & $9.6 \%$ & $\begin{array}{c}1298 \\
(839,1935)\end{array}$ & $\begin{array}{c}2612 \\
(1977,3418)\end{array}$ \\
\hline Wrangel & 108 & 340 & 235 & 283 & 26 ha & $37.9 \%$ & $\begin{array}{c}45^{8} \\
(339,611)\end{array}$ & $\begin{array}{c}1905 \\
(1602,2272)\end{array}$ \\
\hline $\begin{array}{l}\text { Black Sand } \\
\text { Spit }\end{array}$ & 41 & 7 & 24 & 1084 & 312 ha & $12.2 \%$ & $\begin{array}{c}531 \\
(390,697)\end{array}$ & $\begin{array}{c}622 \\
(469,795)\end{array}$ \\
\hline
\end{tabular}

the minimum altitude required to recognize terns, much less identify them to species, made it impractical to cover the entire island. Instead, we employed a sampling approach, based on polygons traced beforehand from Google Earth imagery (Table I, Figure 3). Sample locations were selected based on spatially balanced acceptance sampling (BAS, Robertson et al. 2013), covering between $10 \%$ and $38 \%$ of the island areas, respectively (Table 1, Figure 3). To maximize photos taken during the limited airtime available, we treated the order of pre-defined samples as an openended travelling salesman problem, solved exactly using the Concorde algorithm (Applegate et al. 2006).

By area, Black Sand Spit was the largest colony sampled. Given our previous experience, we improved on the sampling protocol. Instead of individual random points, we sampled along parallel strips, selected using the same BAS algorithm. This allowed us to take photographs on the move, rather than at a small number of predetermined waypoints, dramatically increasing the number of photographs obtained relative to airtime. Flight plans were prepared beforehand and uploaded to the sUAS in the field, using Litchi and GSPro software running on an iPad. While under constant supervision of the certified pilot and an observer, the sUAS flew the missions autonomously. Exposure settings and flight speed were selected to keep motion blur below $2 / 3$ of the ground sampling distance (pixel size). A - $-0.7 \mathrm{EV}$ exposure correction was applied to better preserve details of light-coloured target birds on a comparatively dark background.

We flew 13-3om above ground level (AGL), with an intent to optimise resolution and maximize detection rate. AGL was a compromise between the need to achieve sufficient resolution to reliably recognize terns and to identify them to species (principally by the white forehead patch characteristic of Aleutian Terns), and the need to maintain sufficient altitude that birds would not flush. Previous studies demonstrated that Aleutian Terns did not flush at a small Alaskan colony in response to flights at this altitude (Magness et al. 2019). Images were automatically geotagged by the sUAS.

\section{Photo counting methods}

We enumerated birds (separately, flying, and on the ground) and when possible, unattended nests, in all photographs. Observers marked individual terns (attempting to identify to species) and nests on separate layers using the open-source GNU Image Manipulation Program (GIMP 2.10.10; available at www.gimp.org). We created a new GIMP file for each photo. The image file was imported to a base layer with each category of observations given a different layer. A dot was placed over each bird or nest, and the total number of dots was counted by the software. 


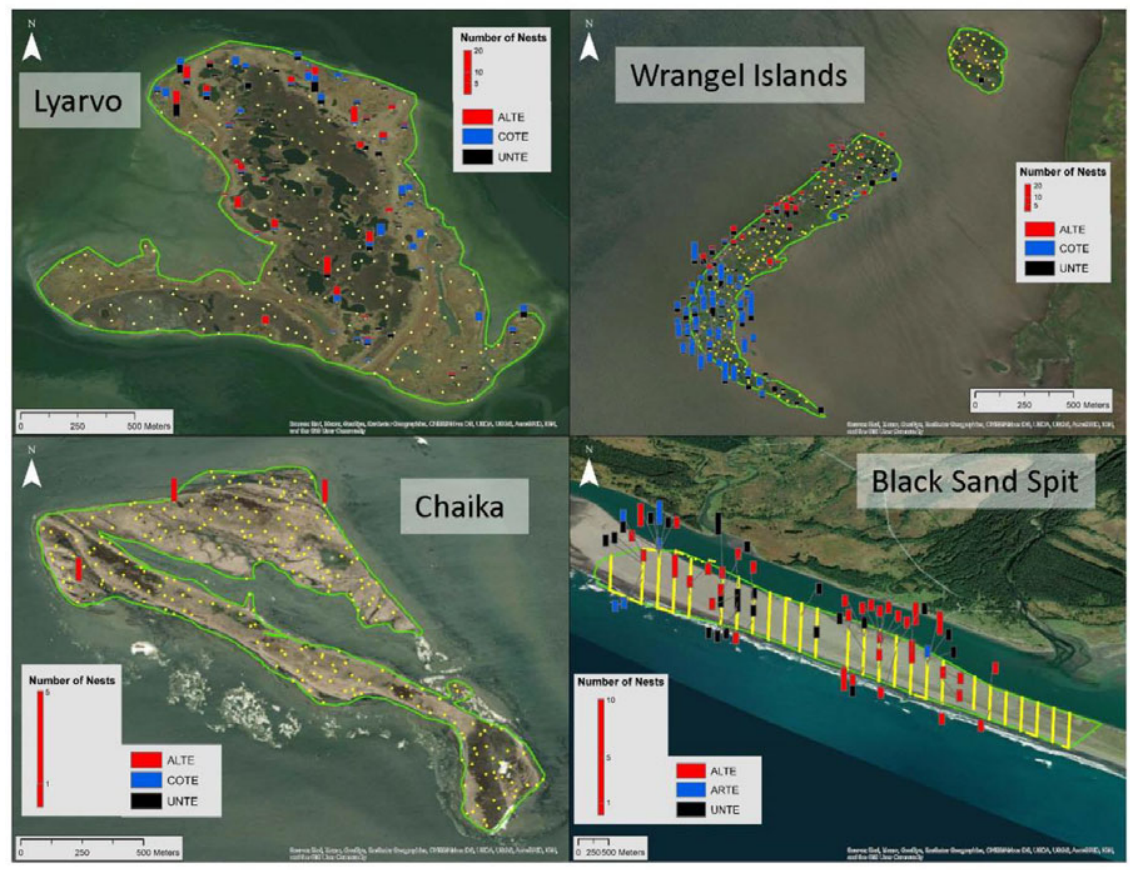

Figure 3. Aleutian Tern colonies surveyed in 2018-2019. Yellow dots indicate aerial photograph sample locations, and bar charts show numbers of nests detected in photographs.

A subset of 150 systematically assigned photos from Wrangel and Lyarvo islands was processed by a second observer to assess the likelihood of either missing birds or identifying an erroneous target as a tern.

\section{Statistical methods for population estimation from sUAS sample points}

The area covered by each image was calculated from sensor dimensions and AGL, extracted from embedded EXIF-data using the formula:

$$
\text { area }=\text { sensorarea } \frac{\text { focallength }}{A G L}
$$

The Phantom 4 Pro sensor measures 0.0132 $\mathrm{m} \times 0.0088 \mathrm{~m}$.

Each image was treated as a local sample of density and species ratio. While some images also showed flying birds, we only used birds on the ground in this analysis. Quantifying flying birds from the sUAS would be impractical, as birds frequently fly higher than the sUAS. We postulate that the birds on the ground are primarily attending their nests. Those birds included birds identified as Aleutian Tern, Common/Arctic Tern, and unidentified terns. To calculate an estimate for the total number of Aleutian Terns per colony, we multiplied the average density of Aleutian Terns (identified Aleutian Terns plus pro-rated unidentified terns) per image $a p_{i}$ with the area of the respective colony polygon. The $95 \% \mathrm{CI}$ were derived from 10,00o bootstrap replicates, using adjusted percentiles. 


$$
a p_{i}=a_{i}+u_{i} \frac{\sum_{i}\left(a_{i}\right)_{i=0}^{i=n}}{\sum_{i=0}^{i=n}\left(a_{i}+c_{i}\right)}
$$

Where $a p_{i}$ is the number of Aleutian Terns per image $i, a_{i}$ is the number of identified Aleutian Terns per image, $u_{i}$ the number of unidentified terns per image, and $c_{i}$ the number of Common/ Arctic Terns per image. Bootstrap estimates included the calculation of the proportion of Aleutian Terns to prorate unidentified terns.

\section{Results}

\section{Visual observations}

On Chaika Island, we estimated from the ground that 300-400 individual terns (Aleutian and Common together) were present during our visits. During our single walk across the island, typically, around 100 terns were visible in the air at any given time. During disturbances, up to 200 terns were visible in the air. We were unable to develop a quantitative species composition estimate, due to apparent variability throughout the day. However, we noted that most or all birds with nests were Aleutian Terns, with much larger numbers of flying Common Terns attending sporadically. A small portion of terns present were incubating eggs at nests, whereas most nests encountered were destroyed. We found abundant sign of predators (brown bear Ursus arctos) including recently dug-up vegetation and tracks. We opportunistically found 12 nests (mostly 1 egg clutches) and $\sim 30$ depredated eggs.

On Lyarvo Island, we estimated that there were c.1,500 terns on the island with a plausible range of $1,000-2,000$. Based on identifying terns in the air to species at 18 roughly equally spaced sampling points across the island, we estimated that c. $56 \%$ of terns present were Aleutian Terns. Attended nests of both species were found in numerous areas across the island. Evidence of predators was less widespread than at Chaika Island (dug-up soil, hair, but few destroyed nests).

Although we did not quantitatively assess tern colony size using counts of flushing individuals on the Wrangel Islands due to the potential for adverse impacts to the high-density colony from flushes, we did visually confirm active nests of both species on Wrangel Major Island (the larger and southernmost of the two islands), and our brief observations suggested fewer terns were present than reported in recent years. Only Aleutian Terns were nesting on Wrangel Minor, whereas Wrangel Major was split between primarily Aleutian Terns nesting on the northern half and primarily Common Terns nesting on the southern half.

On Black Sand Spit, regular surveys were conducted at least once each year by local observers (I3 surveys annually from 2017 to 2019), with the objective for at least one survey to capture the peak attendance/nesting effort. During the flush count survey closest to our sUAS survey (20 June), 1,003 Aleutian Terns and 287 Arctic Terns were estimated. A few days later an estimated 300 flying terns (species combined) were observed based on repeated counts from a distant (mainland) observation point.

\section{Transect based nest counts}

Observers located 81 Aleutian Tern nests in the 2-m-wide transect on Wrangel Major, and 164 Common Tern nests during the 25 June 2018 surveys. We present only 2018 estimates here for comparison with our sUAS surveys. Extrapolated estimates for the entire area (both Wrangel Major and Minor) were 982 Aleutian Tern nests, and 1,861 Common Tern nests. Only 63 of those Aleutian Terns were on Minor Wrangel (no Common Terns). On 3 July, 1,513 Aleutian Tern nests were estimated on Major Wrangel, showing a 54\% increase from June 25. Minor Wrangel was not re-surveyed on 3 July. 


\section{sUAS surveys}

Flushing of terns by the sUAS was not observed on Chaika, Lyarvo, or Black Sand Spit. On the Wrangel Islands, gull flushing (Black-headed Chroicocephalus ridibundus, Black-tailed Larus crassirostris, Slaty-backed L. schistisagus, Glaucous L. hyperboreus, and Common (Kamchatka) gulls L. (canus) kamtschatschensis) was evident during sUAS flights and appeared to cause some tern flushing during sUAS surveys, despite sUASs being flown at heights which previously had not elicited a tern flush response elsewhere.

sUAS surveys provided first population estimates with quantifiable errors for the four largest known Aleutian Tern colonies. Of these, with almost 1,300 Aleutian Terns, Lyarvo was by far the largest colony (Table 1 ). The range of $95 \%$ confidence intervals, relative to the size of the best estimate was negatively related to the number of Aleutian Terns counted.

In the sampled photos ( $n=1,890$ combined from four colonies), we identified 915 individual terns on the ground as well as 81 unattended nests with eggs (Table 1 ). All of these terns were separated by at least one body length, suggesting they did not represent both partners of a nest. Of these totals, $23 \%$ were identified as Aleutian Terns, $44 \%$ as Common/Arctic Terns, and $33 \%$ unidentified terns. Maximum densities of tern nest sites varied considerably, among colonies and by species when known, with up to 22 nest sites in a photo (equivalent to 0.063 nests $\mathrm{m}^{-2}$, given a mean photo area of $350 \mathrm{~m}^{2}$ ). In addition, we identified 195 flying terns in the photographs, which were not included in the analyses.

\section{Photo evaluations by second observer}

Sixty-seven of the 150 photos evaluated by two observers had at least one tern detected in them. Within those, 274 terns were found by one or both observers, plus three that one observer called a tern, and the other observer called a gull (2) or other (I).

Eight terns were found by Observer A but not Observer B, and 15 terns were found by Observer $\mathrm{B}$ but not Observer A ( 3 and $6 \%$ of birds missed; type II error). None of these were determined to be false positives (type I error).

Of the 251 terns found by both observers, there was species agreement on $73 \%$ (24 Aleutian Tern, 133 Common Tern, 25 unidentified tern). For $3 \%$ ( 8 birds), both observers made a species determination as either Common Tern or Aleutian Tern, but they conflicted. Twenty-four percent of the birds (6I) were considered identifiable by one observer but not the other; 20 were called Aleutian Terns and ${ }_{41}$ Common Terns by the more confident observer.

\section{Comparison of abundance estimates}

A comparison of abundance estimates of all tern species combined is shown in Table 2. As expected, visual estimates of flushed birds were higher than sUAS estimates of incubating birds at Chaika and Black Sand Spit - but not at Lyarvo. At Black Sand Spit, the distant flying birds count (assumed to be attending mates) of 300 , plus the sUAS estimate (assumed to be incubating birds) of 622 , approached the flush count estimate $(1,290)$. The flying bird count should be considered a low estimate, given it was from one vantage point at quite a distance. We found it reasonable that the estimate from the sUAS plus the estimated 300 in the air was relatively close to but less than the flush count estimate.

The nest transect estimate was expected to be most similar to our sampled sUAS estimate, because they were one day apart, and both directly estimated nests on a relatively small island. Instead, we found considerably fewer birds in the drone imagery.

\section{Discussion}

We conducted field surveys at the four largest known Aleutian Tern colonies, three in the Russian Far East on Sakhalin Island, and one in Alaska. Together they may represent 30-50\% of the world's 
Table 2. Comparison of colony abundance estimation methods on four mixed species tern colonies in 2018 (Russia) and 2019 (Alaska). All estimates are tern species combined. sUAS counts of birds on the ground + nests with eggs but no attending adult are assumed to approximate nesting pairs. Flush counts (visual) are assumed to include incubating birds, plus some non-attending mates and some non-breeders. The distant vantage flying birds estimate is assumed to be attending partners of incubating birds, plus any nonbreeders. ALTE = Aleutian tern, COTE = common tern.

\begin{tabular}{|c|c|c|c|c|c|}
\hline & $\begin{array}{l}\text { sUAS (nesting } \\
\text { pairs) }\end{array}$ & $\begin{array}{l}\text { visual } \\
\text { (flying) }\end{array}$ & $\begin{array}{c}\text { nest } \\
\text { transect }\end{array}$ & $\begin{array}{c}\text { ALTE in Visual } \\
\text { observation }\end{array}$ & $\begin{array}{c}\text { ALTE in sUAS } \\
\text { photos }\end{array}$ \\
\hline Chaika & $19(6,56)$ & 350 & N/A & $\begin{array}{c}\text { mostly ALTE nesting, } \\
\text { COTE flying }\end{array}$ & $100 \%$ \\
\hline Lyarvo & $\begin{array}{c}2612(1977 \\
3418)\end{array}$ & 1500 & N/A & $56 \%$ & $50 \%$ \\
\hline Wrangel & $\begin{array}{c}1905(1602 \\
2272)\end{array}$ & $\mathrm{N} / \mathrm{A}$ & 2843 & $33 \%{ }^{3}$ & $25 \%$ \\
\hline $\begin{array}{l}\text { Black Sand } \\
\text { Spit }\end{array}$ & $622(469,795)$ & $\begin{array}{r}1290^{1} ; \\
300^{2}\end{array}$ & N/A & $78 \%$ & $87 \%$ \\
\hline
\end{tabular}

${ }^{1}$ 2o June flush count estimate

230 June distant vantage flying birds estimate

3 Species ratio from nest transect, different methods than visual counts.

known population. We provide the first reproducible population estimates with quantifiable errors for several of these colonies, based on pseudo-random sampling the total area with an autonomous sUAS as well as visual estimates. Our population estimates represent single-year snapshots that are susceptible to stochastic events, like bear predation. That said, the numbers of nesting Aleutian Terns found by us were substantially lower than the numbers reported previously (e.g. Tiunov and Blokhin 2014).

\section{sUAS Methodological considerations}

Statistically sampled, low altitude sUAS images provided a fast, reproducible, and rigorous estimate of abundance for geographically large tern colonies, with low disturbance. Concurrence among observers in photo counts indicated high precision in counts of birds $(<6 \%$ missed by each observer, and zero false positives). Although flushing by sUAS is typically not a problem in Aleutian Tern colonies, we did have this issue at Wrangel Island due to the presence of significant numbers of roosting, non-breeding gulls. At no other site did we notice large numbers of roosting gulls, and Slaty-backed and Black-tailed gulls actively nesting at Lyarvo Island did not flush when the sUAS passed directly overhead during surveys there. At Wrangel, it appeared that the roosting gulls readily flushed in reaction to the sUAS approach, causing nearby terns to flush as well. Differential responses of seabirds to sUAS surveys depending on breeding status has previously been reported (Brisson-Curadeau et al. 2017), and our observations were consistent with that finding. Surprisingly, we were able to detect a considerable number of eggs (unattended nests) in the high-resolution imagery, despite their cryptic coloration. Nevertheless, we presume that there were many more nests potentially hidden under vegetation or simply missed, that contributed to the discrepancy between the sUAS-based and nest-transect based estimates.

Reducing the proportion of unidentified terns is a key priority to narrow the confidence intervals for sUAS Aleutian Tern abundance estimates. Flying at 15m AGL was already problematic at Wrangel, so reducing flight altitude may not work, at least at some locations. An alternative would be to improve camera resolution. This would also require a slow-down in speed to avoid motion blur, reducing the number of images available per battery charge. This approach would therefore be in direct conflict with the other option, which is to increase the number of sampled images. 
Constraints to flight time are weather windows (this was an issue at Lyarvo due to precipitation and fog), and available batteries.

Because the calculation of the area of the sampled photograph depends on the height AGL of the sUAS, it would be helpful to quantify potential error or bias. Although our sUAS had a barometric altimeter, we do not have an estimate of its accuracy or precision. A laser rangefinder (Dawson et al. 2017 ) and/or survey-grade on-board GPS/GNSS system would be worth exploring.

Selection of the most useful count metric (nests, flushed birds in the air, sampled or whole colony sUAS survey; Table 3) for population size estimation will depend on the nesting status of the majority of birds present, as well as colony extent and density. Counts of nests are expected to have less within-day and day-to-day variability than counts of birds, although we have observed high variability throughout the season due to timing of laying, mass predation events and frequent colony abandonment. For a variety of reasons (low disturbance, documentation, reproducibility, potential for double blind on species ID; Table 3) we recommend sUAS surveys during the incubation period for large colonies; the spatial extent of the colony and available resources would dictate whether statistical sampling or an entire-colony survey is more appropriate. We postulate that within a colony, the counts of birds on the ground should approach the number of nesting pairs. Nest camera data from 14 nests on Kodiak Island indicated that during the incubation period, single birds were present on nests $80 \%$ of the time during the day and $86 \%$ at night (Jill Tengeres, Oregon State University, unpubl. data). These nests were primarily from 2017-2018 when hatching success was very low; presumably attendance rates are higher when hatching success is more favourable. If roosting birds are present in the colony and not flushed by the sUAS, they would be available to be

Table 3. Comparison of survey methods used for Aleutian Terns.

\begin{tabular}{|c|c|c|c|}
\hline Survey type & What is counted & Pros & Cons \\
\hline Flush count & $\begin{array}{l}\text { Attending birds } \\
\text { plus some non- } \\
\text { attending mates } \\
\text { and some } \\
\text { nonbreeders }\end{array}$ & $\begin{array}{l}\text { Fast, inexpensive, no post- } \\
\text { processing }\end{array}$ & $\begin{array}{l}\text { Poor reproducibility, high } \\
\text { disturbance, no error } \\
\text { estimate without repeated } \\
\text { counts (i.e. flushes) and/or } \\
\text { multiple independent } \\
\text { observers. }\end{array}$ \\
\hline $\begin{array}{l}\text { Distant vantage } \\
\text { count of flying } \\
\text { birds }\end{array}$ & $\begin{array}{l}\text { Non-attending } \\
\text { mates and } \\
\text { nonbreeders }\end{array}$ & $\begin{array}{l}\text { Fast, inexpensive, no post- } \\
\text { processing, no disturbance }\end{array}$ & $\begin{array}{l}\text { Poor reproducibility and high } \\
\text { variability. Uncertain } \\
\text { interpretation. Technically } \\
\text { impractical for large } \\
\text { colonies. }\end{array}$ \\
\hline sUAS - sampled & $\begin{array}{l}\text { Attending birds and } \\
\text { unattended nests } \\
\text { + roosting birds }\end{array}$ & $\begin{array}{l}\text { Moderate effort, low } \\
\text { disturbance, documented, } \\
\text { reproducible, allows for } \\
\text { error estimate, allows } \\
\text { double blind on species ID }\end{array}$ & $\begin{array}{l}\text { Some post processing, sUAS } \\
\text { not allowed everywhere, } \\
\text { licensing and permitting } \\
\text { onerous, weather } \\
\text { dependent }\end{array}$ \\
\hline $\begin{array}{l}\text { sUAS - full } \\
\text { coverage }\end{array}$ & $\begin{array}{l}\text { Attending birds and } \\
\text { unattended nests } \\
\text { + roosting birds }\end{array}$ & $\begin{array}{l}\text { Low disturbance, documented, } \\
\text { reproducible, allows } \\
\text { reproducible count of all } \\
\text { birds and nests, allows } \\
\text { double blind on species ID }\end{array}$ & $\begin{array}{l}\text { Extensive post processing, } \\
\text { high battery time, sUAS not } \\
\text { allowed everywhere, } \\
\text { licensing and permitting } \\
\text { onerous, weather } \\
\text { dependent }\end{array}$ \\
\hline $\begin{array}{l}\text { Nest count } \\
\text { transect }\end{array}$ & Nests & $\begin{array}{l}\text { Moderate effort, inexpensive, } \\
\text { little post processing, low } \\
\text { within-day variability, least } \\
\text { ambiguous metric }\end{array}$ & $\begin{array}{l}\text { High disturbance, impractical } \\
\text { in most locations due to low } \\
\text { density, relies on species ID } \\
\text { by eggs. Unknown } \\
\text { repeatability between } \\
\text { observers. }\end{array}$ \\
\hline
\end{tabular}


counted as well; however, we believe this is a rare occurrence. We recommend that when possible, observers count Aleutian Terns on the ground with a sUAS as well as total birds observed when naturally flushed, e.g. by predators. Although the sUAS count is most statistically robust, the visual estimate provides a useful backup in the event of any missed coverage, inadequate photographs, or nesting failure causing few birds to be on the ground.

Our abundance calculation assumes species identification is unbiased, i.e. that a Common/Arctic Tern is just as likely determined as unidentified as an Aleutian Tern. We speculate that Aleutian Terns are more often assigned a positive identification than Common or Arctic Terns because seeing their white forehead patch is definitive for breeding birds (2nd year Arctic Terns are rare and don't breed; Hatch 2002). If that is the case, our estimate may be slightly higher than the true number of Aleutian Terns. When distinguishing Aleutian from longipennis Common Terns we have the added difficulty that both species have black bills. In Arctic Terns the red bill is evident in many images, which should reduce such bias.

Species ratios of Aleutian to either Common or Arctic Terns are problematic in these mixed species colonies regardless of census method. We recommend field-based methods (visual and aural detections at multiple survey points) to augment species ratio estimates from sUAS imagery. If it can be established that the two species vocalize at a similar rate and where extended or multiple visits are possible, acoustic monitors (Borker et al. 2014) may aid in this estimate.

Correctly assessing the spatial extent of the colony prior to enumeration is important to accurate abundance estimation regardless of survey methodology. Using a sUAS may allow greater flexibility in surveying a large colony's spatial extent than other methods which may be limited by sight line obstructions, distance, or inaccessible terrain. Importantly for Aleutian Terns, sUAS surveys provide reproducible and more easily documented results, and minimize disturbance in most cases. Low disturbance surveys of spatially large colonies are particularly difficult to achieve with ground-based methods.

We sampled colony extent using spatially balanced acceptance sampling (BAS, Robertson et al. 2013); other sampling approaches based on habitat or clustering could also be explored but would likely require more detailed preparations and/or advance knowledge of the colony. We speculate that spatial sampling will become more common in sUAS wildlife surveys in the future and that sampling approaches will undergo significant refinement. Of course, for colonies with small spatial extents, photographing the entirety of the colony would be feasible and preferable in most cases to spatial sampling. Sampling strips (as in Black Sand Spit) rather than random points, allowed us to increase the number of usable images per battery charge at least two-fold. Similarly, for compact colonies with predictable lower abundance (e.g. 50-100 individuals), visual flush counts are likely adequate.

\section{Implications for range-wide Aleutian Tern abundance estimates}

Our one-time counts provided essential information, but only limited context is available on whether our observations were representative of other recent years. Regular visits are made to the Wrangel Islands and Black Sand Spit that can aid in our interpretation, however. On the Wrangel Islands, nest initiation was late in 2018 compared to other years since 2008 (Zykov and Revyakina 2019), with significantly (60\%) higher counts a week later than the standard census period. Gull predation was also high in 2018 , with more than $25 \%$ of all eggs lost in a single week. In contrast, in our survey year on Black Sand Spit (2019), Aleutian Terns nested successfully - the first observation of success in recent years, and the flush count of 1,003 terns on 20 June, following one of 1045 terns on June 7, was higher than in many recent years. Annual June nesting estimates ranged from 368 to 1,229 terns in 2014-2018, with a previous high of 2,061 terns in 2013 (S. Oehlers unpubl. data). Aleutian Tern attendance at Black Sand Spit is highly variable in general, with early season colony failure and abandonment documented in most years, and counts approaching or exceeding 2,000 terns in some other years, since regular monitoring began in the early 2000 s (Oehlers unpubl. data). In 2019, a large number of Aleutian Terns $(>1,000)$ were 
persistently observed across the breeding season (Oehlers 2020), whereas in other recent years numbers declined throughout the season with widespread breeding failure.

Predation is a frequent cause of breeding failure at Aleutian Tern colonies (North 2013, Oehlers unpubl. data, R. Corcoran, unpubl. data). One reported effect of significant human presence in Piltun Bay associated with oil and gas development, is a dramatic reduction in brown bear presence around the lagoon and on the Wrangel Islands over the last 20 years (VZ unpubl. data). While predation used to be common on Wrangel, as it still is at other locations, it is now virtually unheard of. Inadvertently, the industrial development in Piltun Bay may have led to protection and increased breeding success of nesting terns (however, in 2018 we observed lower numbers than previous years). This may also be the reason for the nesting density on Wrangel being multiple times higher than on any of the other sites investigated here, or any other Aleutian Tern colony that we are familiar with.

Our results indicate that the four colonies surveyed here together supported $<2,500$ pairs of Aleutian Terns in the survey years 2018-2019. None of the Russian colonies approached their peak size reported in previous years (Tiunov and Blokhin 2014; see Study Area), likely due to widespread predation, or cold early season weather. The transect-based survey conducted on 25 June to estimate total nest abundance ( 982 Aleutian Terns) indicated a decline in nesting from recent years (see Zykov and Revyakina 2019). By contrast, Black Sand Spit was surveyed in an exceptionally good year, compared to the previous five years that saw suspected complete breeding failure. If these reduced colony sizes reflect persistent conditions, that would present dire implications for the global population. At best, intermittently depressed numbers at these historically large colonies would necessitate significant capacity and opportunity for renesting within a season (suspected at some level but not documented or quantified), require capacity for rapid relocation of tern nesting to alternative sites with suitable habitat, or indicate a significantly smaller effective (breeding) population size than the estimated adult population size for this species. Many species of terns are known to occur in metapopulations, some with the capacity to rapidly shift nesting location based on weather conditions, colony disturbance, or other stressors (Ackakaya et al. 2003, Velarde et al. 2015, Seward et al. 2019). The degree to which Aleutian Terns may display this behaviour is unknown, however. We were not able to systematically survey the regions surrounding these four colonies to potentially detect any other large colonies during the years of our study, but prior regional survey efforts have not identified other colonies of comparable size (Tiunov and Blokhin 2014).

Several potential long-term objectives have been prioritized as a result of engagement between U.S. and Russian biologists. Continued collaborative efforts to evaluate and standardise new methods to estimate colony size (e.g., aerial imagery collected using sUASs) would greatly benefit population assessments both in Alaska and Russia. Additional surveys of important nesting areas on Sakhalin Island would also be valuable, both to investigate lower-than-expected numbers seen in our survey and to monitor this critical component of the range-wide Aleutian Tern population. Detailed information on demography (e.g. nest success rates) and colony attendance across the breeding season would inform risk assessment and methods to estimate abundance. Finally, a population genetics study investigating rates of exchange between Russia and Alaska could help interpret declines seen at known colonies in Alaska.

\section{Acknowledgements}

The field work in Russia was logistically challenging and would not have been possible without the generous cooperation and participation of multiple Russian collaborators. Pavel Ktitorov provided logistical support in preparation for the field work, field equipment, and useful advice. Larisa Zelenskaya participated in the surveys on Chaika and Lyarvo Islands and provided logistical and translation assistance. Ivan Tiunov provided guidance on survey locations and logistics. Evgeny Syroechkovskiy provided guidance on how future collaborative work could be developed. We thank ExxonMobil, in particular Exxon Neftegas Limited as Operator of the Sakhalin-1 Project, for 
sponsoring production of Wrangel Island nest survey data and for their release into the scientific literature. Peter Ward assisted with Russian travel logistics and visas. Janelle Lopez assisted in the field at Black Sand Spit. Mike Goldstein facilitated sUAS work on US Forest Service lands. sUAS photos were counted by Erin Lefkowitz and Jane Dolliver; Melissa Petschauer compared their observations on individual birds. Nora Rojek helped produce figures. We also thank Trent McDonald for discussions on sampling design. Field work in Russia was funded by a USGS Science Support Partnership grant to Dan Roby. Alaska field work was funded by the National Fish and Wildlife Foundation, Pacific Seabird Program, with special thanks to Scott Hall. The findings and conclusions in this article are those of the authors and do not necessarily represent the views of the U.S. Fish and Wildlife Service.

\section{References}

Akçakaya, H. R., Atwood, J. L., Breininger, D., Collins, C. T. and Duncan, B. (2003) Metapopulation dynamics of the California least tern. J. Wildl. Manage. 67: 829-842.

Applegate, D., Bixby, R., Chvátal, V. and Cook, W. (2006) Concorde TSP Solver. URL http://www.tsp.gatech.edu/concorde/.

Baicich, P. J. and Harrison, J. O. (2005) Nests, eggs, and nestlings of North American birds. Second Edition. Princeton NJ: Princeton University Press.

Bell, M. and Harborne, P. (2019) The use of an Unmanned Aerial Vehicle to census large breeding colonies of black-billed gull (Larus bulleri) and white-fronted tern (Sterna striata) at the Ashburton River/Hakatere River mouth. Notornis 66: 95-97.

BirdLife International (2021) Species factsheet: Onychoprion aleuticus. Downloaded from http://www.birdlife.org on 12/07/2021.

Borker, A. L., McKown, M. W., Ackerman, J. T., Eagles-Smith, C. A., Tershy, B. R., and Croll, D. A. (2014) Vocal activity as a low cost and scalable index of seabird colony size. Conserv. Biol. 28: 1100-1108.

Brisson-Curadeau, É., Bird, D., Burke, C., Fifield, D. A., Pace, P., Sherley, R. B., and Elliott, K. H. (2017) Seabird species vary in behavioural response to drone census. Sci. Reports 7: 1-9.

Chen, S., Fan, Z., Roby, D. D., Lu, Y., Chen, C., Huang, Q., Cheng, L. and Zhu, J. (2015) Human harvest, climate change and their synergistic effects drove the Chinese Crested Tern to the brink of extinction. Glob. Ecol. Conserv. 4: 137-145.

Corcoran, R.M., Studebaker, S. and Macintosh, R.A. (2018) Aleutian Tern Onychoprion aleuticus colony abandonment in response to Bald Eagle Haliaeetus leucocephalus nest predation. Mar Ornithol. 46: 113-115.

Dawson, S. M., Bowman, M. H., Leunissen, E., and Sirguey, P. (2017) Inexpensive aerial photogrammetry for studies of whales and large marine animals. Front. Mar. Sci. 4: 366.

Erwin, R. M., Allen, D. H., and Jenkins, D. (2003) Created versus natural coastal islands: Atlantic waterbird populations, habitat choices, and management implications. Estuaries 26: 949-955.

Erwin, R. M., Brinker D. F., Watts, B. D., Costanzo, G. R., and Morton, D. D. (2010) Islands at bay: rising seas, eroding islands, and waterbird habitat loss in Chesapeake Bay (USA). J. Coastal Conserv. 15: 51-60.

Everaert, J. and Stienen, E. W. M. (2007) Impact of wind turbines on birds in Zeebrugge (Belgium). Biodivers. Conserv. 16: 3345-3359

Goldstein, M. I., Duffy, D. C., Oehlers, S., Catterson, N., Frederick, J. and Pyare, S. (2019) Interseasonal movements and nonbreeding locations of Aleutian Terns Onychoprion aleuticus. Mar. Ornithol. 47: $67-76$.

Hatch, J. J. (2002) Arctic Tern (Sterna paradisaea). In P. G. Rodewald, ed. The birds of North America. Ithaca, NY, USA: Cornell Lab of Ornithology. Retrieved from https:// birdsna.org/Species-Account/bna/species/ arcter. https://doi.org/10.2173/bna.707 
Hays, H., DiCostanzo, J., Cormons, G., Antas, P. T. Z., and do Nascimento, J. L. X. (1997) Recoveries of Roseate and Common Terns in South America. J. Field Ornithol. 68: 79-90.

Hodgson, J. C., Baylis, S. M., Mott, R., Herrod, A. and Clarke, R. H. (2016) Precision wildlife monitoring using unmanned aerial vehicles. Sci. Reports 6: 1-7.

Kress, S. W., Weinstein, E. H., and Nisbet, I. C. T. (1983) The status of tern populations in northeastern United States and adjacent Canada. Colonial Waterbirds 6: 84-106.

Magness, D. R., Eskelin, T., Laker, M. and Renner, H. M. (2019) Evaluation of small unmanned aerial systems as a census tool for Aleutian Tern Onychoprion aleuticus colonies. Mar. Ornithol. 47: 11-16.

McDonald, T., Thompson, J., Gerringer, M., Carlisle, J., Corcoran, R., Skinner, J., Fleishman, A., McKown, M., and Nesvacil, K. (2018) Aleutian Tern colony abundance: 2018 field season. Unpublished report. $105 \mathrm{pp}$.

McDonald, T., Thompson, J., Gerringer, M., Carlisle, J., Tengeres, J. and Corcoran, R. (2019) Aleutian Tern colony abundance: 2019 field season. Unpublished report.

Nacci, D. E., Hahn, M. E., Karchner, S. I., Jayaraman, S., Mostello, C., Miller, K. M., Blackwell, C. G., and Nisbet, I. C. T. (2016) Integrating monitoring and genetic methods to infer historical risks of PCBs and DDE to Common and Roseate terns nesting near the New Bedford Harbor Superfund site (Massachusetts, USA). Environ. Sci. Technol. 50: 10226-10235.

Newton, I. and Little, B. (2009) Assessment of wind-farm and other bird casualties from carcasses found on a Northumbrian beach over an 11-year period. Bird Study 56: 158-167.

North, M. R. (2020) Aleutian Tern (Onychoprion aleuticus), version 1.o. In S. M. Billerman, ed. Birds of the world. Ithaca, NY, USA: Cornell Lab of Ornithology. https:// doi.org/10.2173/bow.aleter1.0I

Oehlers, S. (2020) Summary of Yakutat area 2019 Aleutian tern monitoring. Unpublished report. U.S. Forest Service.
Pyare, S., Goldstein, M., Duffy, D., Oehlers, S., Catterson, N. and Frederick, J. (2013) Aleutian tern (Onychoprion aleutica) research in Alaska: Survey methodology, migration, and statewide coordination. Unpublished report.

Robertson, B., Brown, J., McDonald, T., and Jaksons, P. (2013) BAS: Balanced acceptance sampling of natural resources. Biometrics 69: $776-784$.

Renner, H. M., Romano, M. D., Renner, M., Pyare, S., Goldstein, M. I. and Arthukin, Y. (2015) Assessing the breeding distribution and population trends of the Aleutian Tern Onychoprion aleuticus. Mar. Ornithol. 43: 179-187.

Seward, A., Ratcliffe, N., Newton, S., Caldow, R., Piec, D., Morrison, P., Cadwallender, T., Davies, W. and Bolton, M. (2019) Metapopulation dynamics of roseate terns: Sources, sinks and implications for conservation management decisions. J. Anim. Ecol. 88: $138-153$.

Tiunov, I. M. and Blokhin, A. Y. (2014) The current state of populations of the common tern Sterna hirundo (Linnaeus, 1758) and the Kamchatka tern S. camtschatica (Pallas, 1811) in northern Sakhalin. Russ. J. Mar. Biol. 40: 383-395.

Valle, R. G. and Scarton, F. (2021) Droneconducted counts as a tool for the rapid assessment of productivity of Sandwich Terns (Thalasseus sandvicensis). J. Ornithol. 162: 621-628.

Velarde, E., Ezcurra, E., Horn, M. H. and Patton, R. T. (2015) Warm oceanographic anomalies and fishing pressure drive seabird nesting north. Sci. Advances 1: p. e1400210.

Walker, E. P. (1923) Definite breeding record for the Aleutian tern in southern Alaska. The Condor 25: 113-117.

Yordan, K., Emannuel, B., Tirtaningtyas, F. N., Pyare, S., and Goldstein, M. I. (2019) Locating and identifying non-breeding Aleutian tern Onychoprion aleuticus in Indonesia. Birding Asia 31: 28-32.

Zykov, V. and Revyakina, Z. (2019) Monitoring of the Aleutian and common terns in north-east of Sakhalin Island. Unpublished report. ExxonMobil. 